\title{
ERRATUM
}

DOI: $10.3892 /$ ijo.2020.4971

Long non-coding RNA KCNQ1OT1 mediates the growth of hepatocellular carcinoma by functioning as a competing endogenous RNA of miR-504

CHAO LI, RUNCHEN MIAO, JINGYAO ZHANG, KAI QU and CHANG LIU

Int J Oncol 52: 1603-1612, 2018; DOI: 10.3892/ijo.2018.4313

Following the publication of this article, the authors have realized that Table I was not included with the printed version of the article, although it was referenced in the text. Subsequently, it has been determined that a processing error or oversight must have been made during the pre-press stages.

Table I, as it should have appeared in this paper, is shown in the next page. We apologize to the authors for this omission, and regret the inconvenience that this has caused. c) (i) This work is licensed under a Creative Commons
Attribution 4.0 International (CC BY 4.0) License. 
Table I. Clinical and pathological factors associated with KCNQ1OT1 expression in 50 patients with HCC.

\section{KCNQ1OT1 expression}

\begin{tabular}{|c|c|c|c|c|}
\hline Clinical characteristic & Low $(n=22)$ & High $(n=28)$ & Chi-square & P-value \\
\hline \multicolumn{5}{|l|}{ Gender } \\
\hline Male & 12 & 18 & 0.487 & 0.485 \\
\hline Female & 10 & 10 & & \\
\hline \multicolumn{5}{|l|}{ Age (year) } \\
\hline$<50$ & 9 & 17 & 1.936 & 0.164 \\
\hline$\geq 50$ & 13 & 11 & & \\
\hline \multicolumn{5}{|l|}{$\mathrm{HBsAg}$} \\
\hline Negative & 9 & 6 & 2.226 & 0.136 \\
\hline Positive & 13 & 22 & & \\
\hline \multicolumn{5}{|l|}{ Liver cirrhosis } \\
\hline Absent & 14 & 9 & 4.919 & $0.027^{*}$ \\
\hline Present & 8 & 19 & & \\
\hline \multicolumn{5}{|l|}{ Serum AFP (ng/ml) } \\
\hline$<400$ & 10 & 7 & 2.297 & 0.130 \\
\hline$\geq 400$ & 12 & 21 & & \\
\hline \multicolumn{5}{|c|}{ Edmondson-Steiner grading } \\
\hline $\mathrm{I}+\mathrm{II}$ & 15 & 12 & 3.181 & 0.075 \\
\hline III+IV & 7 & 16 & & \\
\hline \multicolumn{5}{|l|}{ Tumor size } \\
\hline$<5 \mathrm{~cm}$ & 18 & 9 & 12.239 & $<0.001^{*}$ \\
\hline$\geq 5 \mathrm{~cm}$ & 4 & 19 & & \\
\hline \multicolumn{5}{|l|}{ Venous infiltration } \\
\hline Absent & 17 & 15 & 3.004 & 0.083 \\
\hline Present & 5 & 13 & & \\
\hline \multicolumn{5}{|l|}{ TNM stage } \\
\hline $\mathrm{I}+\mathrm{II}$ & 15 & 7 & 9.323 & $0.002^{*}$ \\
\hline III + IV & 7 & 21 & & \\
\hline
\end{tabular}

HBsAg: Hepatitis B surface antigen; HCC, hepatic cellular carcinoma; TNM: tumor-node-metastasis. ${ }^{*} \mathrm{P}<0.05$ 